\title{
NGHIÊN CỨU SẢN XUẤT MỌTT SỐ CHỦNG VI KHUẨN DẠNG ĐÔNG KHÔ TRONG KIỂM TRA CHẤT LƯỢNG XÉT NGHIẸM VI SINH
}

\author{
Phan Văn Hiếu1, ${ }^{1,}$, Vũ Thị Bích Hồng ${ }^{1}$, Đặng Thị Ngọc Dung ${ }^{1,3}$, \\ Đoàn Mai Phương ${ }^{2}$ và Nguyễn Xuân Đạt ${ }^{1}$
}

${ }^{1}$ Trung tâm Kiểm chuẩn chất lượng xét nghiệm y học - Trường Đại học Y Hà Nội,

${ }^{2}$ Bệnh viện Vinmec Times City,

${ }^{3}$ Bộ môn Hóa sinh - Trường Đại học Y Hà Nội.

Nghiên cứu sản xuất các mẫu kiểm tra chất lượng vi sinh bằng dạng đông khô để cung cấp cho các phòng xét nghiệm trong nước nhằm nâng cao chất lượng xét nghiệm. Nghiên cứu thực hiện trên thiết bị đông khô Virtis Advantage Pro SP Scientific đối với 3 chủng vi khuẩn Staphylococcus aureus ATCC 29213, Escherichia coli ATCC 25922 và Pseudomonas aeruginosa ATCC 27853 với dung dịch bảo vệ là Skimmilk 20\%. Sản phẩm đông khô được đánh giá các tiêu chuẩn về đặc tính vật lý, độ sống, độ ẩm tồn dư, độ vô khuẩn, độ đồng nhất và độ ổn định trong vòng 6 tháng. Kết quả thu được cho thấy tất cả lọ sản phẩm đông khô thu được thỏa mãn các tiêu chí chất lượng đề ra về mặt cảm quan, tính háo nước, độ tơi xốp. Các mẫu kiểm tra có độ sống $\geq 103 \mathrm{CFU} / \mathrm{mL}$, độ ẩm tồn $d u$ < 4\%, độ vô khuẩn và độ đồng nhất đạt $100 \%$, mẫu ổn định trong tối thiểu 6 tháng. Như vậy quy trình đông khô áp dụng trong nghiên cứu phù hợp cho mục đích sản xuất mẫu kiểm tra chất lượng xét nghiệm vi sinh dạng đông khô từ 3 chủng vi khuẩn trên.

Từ khoá: Đông khô khuẩn, độ đồng nhất, độ ổn định, độ sống, kiểm tra chất lượng xét nghiệm vi sinh

\section{I. ĐẠT VẤN ĐÊ}

Vấn đề đánh giá năng lực xét nghiệm và nâng cao chất lượng hoạt động của các phòng xét nghiệm lâm sàng là nhiệm vụ quan trọng trong giai đoạn hiện nay được Chính phủ và Bộ $Y$ tế ngày càng quan tâm chỉ đạo và triển khai thực hiện mạnh mẽ. Đề án 316/QĐ-TTg của Thủ tướng về tăng cường năng lực hệ thống quản lý chất lượng xét nghiệm y học giai đoạn 2016 2025 đề ra nhiệm vụ Việt Nam có thể tự nghiên cứu sản xuất các mẫu kiểm tra chất lượng xét nghiệm. ${ }^{1}$ Một trong những yếu tố quan trọng nhất trong kiểm soát chất lượng xét nghiệm vi sinh là phòng xét nghiệm phải thực hiện nội kiểm và ngoại kiểm, cả hai quá trình này đều

Tác giả liên hệ: Phan Văn Hiếu

Trường Đại học Y Hà Nội

Email: phanvanhieu@hmu.edu.vn

Ngày nhận: 15/01/2021

Ngày được chấp nhận: 08/03/2021 cần có các mẫu kiểm tra chất lượng từ chủng vi khuẩn phù hợp để thực hiện. ${ }^{2,3}$ Hiện nay, đa số các phòng xét nghiệm tại Việt Nam sử dụng các chủng chuẩn mua từ nước ngoài hoặc thông qua các đơn vị phân phối trong nước với giá thành cao, thế hệ lớn cũng như gặp khó khăn trong việc lưu giữ chủng làm giảm tính ổn định dài hạn của chủng vi khuẩn. Nghiên cứu sản xuất được bộ mẫu kiểm tra chất lượng vi sinh từ những chủng vi khuẩn gần gũi với đặc điểm bệnh sinh tại Việt Nam để cung cấp cho các phòng xét nghiệm trong nước những giúp giải quyết các hạn chế trên.

Bảo quản chủng vi khuẩn lâu dài bằng phương pháp đông khô đang là phương pháp phổ biến nhất hiện nay và được các tổ chức uy tín như ngân hàng chủng chuẩn Hoa Kỳ ATCC hay ngân hàng chủng chuẩn Anh Quốc khuyến cáo thực hiện. ${ }^{4,5}$ Các tổ chức ngoại kiểm ở các nước phát triển như Đại học Hoàng gia về bệnh 
học của Australia, chương trình thử nghiệm độ thành thạo vi sinh lâm sàng của Canada, dịch vụ ngoại kiểm tra chất lượng quốc gia của Vương quốc Anh cũng đã sản xuất và áp dụng rộng rãi các bộ mẫu ngoại kiểm dưới dạng đông khô. Qua thực tế tham gia trực tiếp vào chương trình ngoại kiểm trên đã cho thấy những ưu điểm vượt trội về mức độ thử thách, độ đa dạng của vi khuẩn, độ ổn định của loại mẫu đông khô. Trước tình hình đó, chúng tôi tiến hành nghiên cứu đề tài này với mục tiêu hoàn thiện quy trình sản xuất và đánh giá chất lượng một số chủng vi khuẩn đông khô sử dụng trong kiểm tra chất lượng xét nghiệm vi sinh.

\section{II. ĐỐI TƯỢNG VÀ PHƯƠNG PHÁP}

\section{1. Đối tượng}

Các chủng vi khuẩn Staphylococcus aureus ATCC 29213 thế hệ F3, Escherichia coli ATCC 29212 thế hệ F1, Pseudomonas aeruginosa ATCC 27853 thế hệ F1.

Tiêu chuẩn chấp nhận: Chủng chuẩn vi khuẩn ATCC thuần nhất, thế hệ từ F0 đến F5 và có lý lịch chủng do nhà sản xuất cung cấp.

Tiêu chuẩn loại trừ: Chủng có kết quả định danh không giống nhà sản xuất công bố trong lý lịch chủng. Kết quả nội kiểm kháng sinh đồ trên máy Vitek 2 Compact không đạt.

\section{Phương pháp}

Thiết kế nghiên cứu: Thực nghiệm trong phòng xét nghiệm.

Thời gian nghiên cứu: Từ tháng 11 năm 2019 đến tháng 08 năm 2020.

Địa điểm nghiên cứu: Trung tâm Kiểm chuẩn Chất lượng Xét nghiệm Y học thuộc Trường Đại học $Y$ Hà Nội và Viện Công nghệ thực phẩm.

Phương pháp chọn mẫu và cỡ mẫu: Chọn mẫu phù hợp với tiêu chuẩn lựa chọn và loại trừ với cỡ mẫu: 50 lọ mẫu/chủng $x 3$ chủng = 150 lọ mẫu.
Các chỉ số nghiên cứu: Đặc tính vật lý, độ ẩm tồn $\mathrm{du}$, độ sống, độ thuần nhất, độ đồng nhất, độ ổn định.

Các bước tiến hành nghiên cứu

Thu thập và kiểm tra đặc tính chủng vi khuẩn trước đông khô: Chủng chuẩn ATCC sau khi hoàn nguyên lên được cấy lên đĩa thạch máu và thạch UTI, nuôi cấy ở điều kiện $35-37^{\circ} \mathrm{C}$ trong vòng 18-24 giờ. Quan sát tính chất khuẩn lạc và đặc điểm nhuộm Gram và thực hiện định danh và kháng sinh đồ trên hệ thống Vitek 2 Compact. Sử dụng thẻ kháng sinh AST-GP67 cho chủng Staphylococcus aureus, thẻ AST-GN92 cho chủng Escherichia coli, thẻ AST-N204 cho chủng Pseudomonas aeruginosa.

Chuẩn bị và phân phối mẫu: Thực hiện gặt chủng vi khuẩn đã nuôi cấy bằng nước muối $0,9 \%$ vô trùng, đo độ đục bằng thiết bị Densicheck plus đảm bảo sao cho độ đục của huyền dịch > 2McF, tiếp tục pha với dung dịch SKimmilk $20 \%$ với thể tích tương đương để thu được huyền dịch vi khuẩn có độ đục $>1 \mathrm{McF}$. Phân phối mẫu bằng cách dùng pipet vô trùng hút $1 \mathrm{ml}$ dịch huyền dịch nhỏ vào đáy ống đông khô, không làm dính dung dịch lên mép hoặc thành ống. Mỗi loài 50 ống. Đồng thời thực hiện cấy đếm để kiểm tra độ sống của các lọ huyền dịch vi khuẩn đã chuẩn bị ở trên.

Đông khô mẫu: Thực hiện đông khô các lọ mẫu đã chuẩn bị trên thiết bị Virtis Advantage Pro SP Scientific với chương trình như sau:

Giai đoạn làm đông: Nhiệt độ - $40^{\circ} \mathrm{C}$, duy trì trong vòng 5 giờ.

Giai đoạn khô cấp một: Nhiệt độ $-30^{\circ} \mathrm{C}$, áp suất 200 mtorr và duy trì trong vòng 10 giờ.

Giai đoạn khô cấp hai: Tăng nhiệt độ lên đến $25^{\circ} \mathrm{C}$ và áp suất 200 mtorr và tổng thời gian 5 giờ.

Đánh giá chất lượng mẫu sau đông khô: 
Sản phẩm sau đông khô được đánh giá các chỉ tiêu về tính chất vật lý, độ ẩm tồn dư, độ thuần nhất, độ đồng nhất ngay thời điểm sau khi đông khô. Độ sống, độ ổn định được đánh giá mỗi tháng 1 lần trong vòng 6 tháng.

\section{Xử lý số liệu}

Số liệu nghiên cứu được xử lý bằng phần mềm Microsoft Excel 2017. Thống kê mô tả được áp dụng để trình bày các tần suất, tỷ lệ \% về chất lượng các mẫu vi khuẩn đông khô trong nghiên cứu.

\section{4. Đạo đức nghiên cứu}

Nghiên cứu thực hiện vì mục đích khoa học. Các chủng vi khuẩn có nguồn gốc rõ ràng và chỉ sử dụng trong quy mô phòng xét nghiệm, quá trình sử dụng, vận chuyển, bảo quản tuân thủ đầy đủ các biện pháp đảm bảo an toàn đối với chất lây nhiễm loại $B$ theo quy định của Bộ Y tế.

\section{KẾT QUẢ}

\section{Kết quả đánh giá chất lượng mẫu sau đông khô}

Tất cả sản phẩm thu được đảm bảo yêu cầu về tính chất vật lý; mẫu đóng bánh đều, màu sắc đồng nhất, xốp mịn, không vón cục, không bị teo vỡ, tan nhanh khi hoàn nguyên (Bảng 1).

\section{Bảng 1. Kết quả đánh giá ban đầu chất lượng mẫu đông khô}

\begin{tabular}{|c|c|c|c|c|}
\hline STT & \multicolumn{2}{|c|}{ Nội dung kiểm tra } & Tiêu chuẩn & Kết quả \\
\hline 1 & \multicolumn{2}{|l|}{ Tính chất vật lý } & $\begin{array}{l}\text { Mẫu đóng bánh đều, màu sắc } \\
\text { đồng nhất, xốp mịn, không vón } \\
\text { cục, không bị teo vỡ, tan nhanh } \\
\text { khi hoàn nguyên }\end{array}$ & Đạt \\
\hline \multirow{3}{*}{2} & \multirow{3}{*}{ Độ ẩm tồn dư } & S. aureus & \multirow{3}{*}{$<4 \%$} & $2,18 \%$ \\
\hline & & E. coli & & $2,65 \%$ \\
\hline & & $P$. aeruginosa & & $1,99 \%$ \\
\hline 3 & Độ thuần nhất & & 100\% thuần nhất & Đạt \\
\hline
\end{tabular}

Độ ẩm tồn dư của các lọ mẫu đông khô được kiểm tra ở cả 3 chủng vi khuẩn đều <4\%, thỏa mãn tiêu chí đề ra theo tiêu chuẩn nghành TCN 34:99 của bộ nông nghiệp và phát triển nông thôn (Bảng 1).

Tất cả lọ mẫu kiểm tra độ thuần nhất quan sát thấy chỉ xuất hiện 1 loại khuẩn lạc, tiêu bản nhuộm Gram đồng nhất một loại vi khuẩn giống với tính chất đặc trưng của chủng gốc ban đầu, không qua sát thấy tạp nhiễm vi khuẩn khác. Kết luận độ thuần nhất của sản phẩm đông khô đạt $100 \%$ (Bảng 1).

\section{2. Đánh giá độ đồng nhất}

Mẫu đông khô được tiến hành kiểm tra độ đồng nhất theo hướng dẫn ISO/IEC 13528: 2015: Lựa chọn ngẫu nhiên 10 lọ mẫu/loài, thực hiện định danh và kháng sinh đồ trên hệ thống Vitek 2 Compact, kết quả định danh các mẫu giống với kết quả định danh của chủng gốc với độ tin cậy của kết quả dao động từ 93\% đến 99\%. Kết quả kháng sinh đồ thu được giống với kết quả kháng sinh đồ chủng trước đông khô và đều thỏa mãn tiêu chuẩn giới hạn QC công bố trong CLSI M100 cập nhật năm 2019. Kết luận độ đồng nhất của mẫu đạt 100\%, thỏa mãn tiêu chí đề ra theo ISO/IEC 13528:2015. 


\section{3. Đánh giá độ sống}

Sản phẩm đông khô được đánh giá độ sống ngay thời điểm sau đông khô và mỗi tháng một lần, mỗi lần 2 mẫu trong vòng 6 tháng. Tổng số lọ mẫu kiểm tra độ sống sau đông khô ở mỗi loài là 14 lọ. Tất cả các chủng đều có mật độ vi khuẩn ở các thời điểm sau đông khô $>10^{3} \mathrm{CFU} / \mathrm{ml}$, thỏa mãn tiêu chí đề ra theo TCVN 9298:2014 là $\geq 10^{3}$ CFU/ml, trong đó S. aureus ATCC 29213 có mật độ vi khuẩn trung bình sau đông khô cao nhất là $2.5 \times 10^{7} \mathrm{CFU} / \mathrm{ml}$ và E. coli ATCC 25922 có nồng độ thấp nhất với mật độ 4.3×104 CFU/ml (Hình 1).

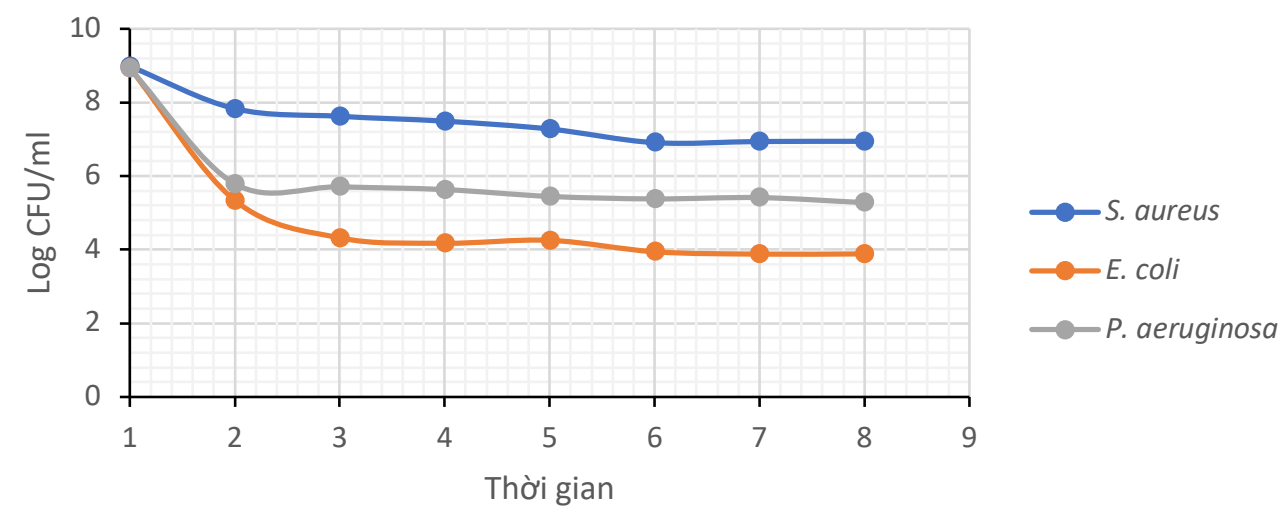

Hình 1. Độ sống của các chủng vi khuẩn đông khô theo thời gian

Chú thích: Mốc thời gian 1 tương đương với thời điểm trước đông khô, mốc 2 tương đương thời điểm kiểm tra độ đồng nhất ngay sau khi đông khô, các mốc từ 3 đến 8 tương ứng với các khoảng thời gian kiểm tra độ ổn định sau khi đông khô lần lượt từ 1 đến 6 tháng.

\section{4. Đánh giá độ ổn định}

Mẫu đông khô được tiến hành kiểm tra độ ổn định theo hướng dẫn ISO/ IEC 13528: 2015: Lựa chọn ngẫu nhiên 2 lọ mẫu/loài sau đông khô, thực hiện định danh và kháng sinh đồ trên hệ thống Vitek 2 Compact mỗi tháng 1 lần trong vòng 6 tháng. Kết quả định danh các mẫu giống với kết quả định danh của chủng gốc với độ tin cậy của dao động từ 93\% đến 99\%. Kết quả kháng sinh đồ thu được giống với kết quả kháng sinh đồ chủng trước đông khô và đều thỏa mãn tiêu chuẩn giới hạn QC công bố trong CLSI M100 cập nhật năm 2019. Như vậy sản phẩm đông khô của cả 3 loài có độ ổn định đạt 100\%, thỏa mãn tiêu chí đề ra theo ISO/IEC 13528:2015. Mẫu ổn định tối thiểu trong vòng 6 tháng.

\section{BÀN LUÂN}

Các đặc tính vật lý của mẫu đông khô là tiêu chí quan trọng ban đầu giúp đánh giá sơ bộ sản phẩm đông khô có đạt chất lượng hay không. Kết quả đánh giá về sản phẩm trong nghiên cứu cho thấy $100 \%$ sản phẩm đóng bánh đều, đẹp, màu trắng ngà, không bị teo, vỡ hay sủi bọt bám lên thành ống, sản phẩm

xốp, mịn, không vón cục và tan hoàn toàn trong vòng 5 phút sau khi hoàn nguyên. Kết quả thu được hoàn toàn phù hợp với tiêu chuẩn quốc gia TCVN 9298:2014 và kết quả nghiên cứu của N.T. Kê và cộng sự năm 1999.5,6

Việc kiểm tra độ ẩm tồn dư được thực hiện tại Trung tâm phân tích và Giám định thực 
phẩm Quốc gia - Viện Công nghệ thực phẩm theo quy trình phân tích của phương pháp thử Tiêu chuẩn Việt Nam TCVN 4846:1989, kết quả đo lường cho thấy lọ có độ ẩm tồn dư cao nhất là $2,89 \%$, thấp nhất là $1,47 \%$ và độ ẩm tồn dư trung bình là $2,27 \%$. Kết quả nghiên cứu của chúng tôi phù hợp với tiêu chuẩn cho chỉ tiêu này đối với sản phẩm đông khô vi sinh vật là vacxin theo quy định của Viện kiểm định Vacxin Quốc gia và Tổ chức y tế Thế giới là $\leq$ $3 \%$ và Quyết định số 03/1999/QĐ-BNN/TCCB ngày 06/01/1999 về việc ban hành tiêu chuẩn nghành về bảo quản ngắn hạn nguồn gien vi sinh vật nông nghiệp (348-99) và bảo quản dài hạn nguồn gien vi sinh vật nông nghiệp bằng phương pháp đông khô (349-99) là < 4\%.7 Độ ẩm tồn dư trong nghiên cứu của chúng tôi cao hơn so với kết quả nghiên cứu của một số tác giả như A. Mehaffey và cộng sự (1984) là < 1\% và nghiên cứu của W . Griffin và C. Cook (1981) là $0,2-0,4 \%{ }^{8,9}$ Đối chiếu lại quy trình đông khô của 2 nghiên cứu trên chúng tôi nhận thấy thời gian của giai đoạn đông khô cấp 2 của cả 2 nghiên cứu đều kéo dài trên 25 giờ, nhiều hơn 5 lần so với thời gian của giai đoạn tương ứng trong nghiên cứu của chúng tôi. Điều này một lần nữa khẳng định tầm quan trọng của thời gian của giai đoạn đông khô cấp 2 liên quan đến độ ẩm tồn dư của sản phẩm.

Kết quả nghiên cứu độ sống cho thấy nhìn chung nồng độ của các chủng vi khuẩn có có xu hướng giảm mạnh ở thời điểm ngay sau khi đông khô và duy trì ổn định ở khoảng thời gian 6 tháng kiểm tra ổn định sau đó, độ sống của cả 3 chủng vi khuẩn ở các thời điểm sau đông khô đều $>10^{3} \mathrm{CFU} / \mathrm{mL}$, phù hợp với tiêu chuẩn đề ra theo TCVN 9298:2014. ${ }^{5}$ Chủng có tỷ lệ sống sau đông khô cao nhất là $S$. aureus dao động từ $77 \%-84 \%$, thấp nhất là $E$. coli dao động quanh $43 \%$ - 48\%. Kết quả nghiên cứu của chúng tôi phù hợp với kết quả nghiên cứu của Yukie Miyamoto-Shinohara và cộng sự (2000). ${ }^{10}$ Kết quả nghiên cứu cũng cho thấy cầu khuẩn $S$. aureus có tỷ lệ sống cao hơn so với 2 trực khuẩn còn lại, kết quả nghiên cứu của chúng tôi phù hợp với kết luận trong nghiên cứu của Kandil S và El Soda M. (2015). ${ }^{11} E$. coli và $P$. aeruginosa là chủng di động có tỷ lệ sống sau đông khô thấp hơn so với chủng không di động là $S$. aureus, kết quả này phù hợp với kết quả nghiên cứu của Morgan CA và cộng sự (2006).12

Độ đồng nhất cao cho thấy quy trình sản xuất ổn định, chất lượng giữa các lọ mẫu là tương đương. Đặc biệt đối với mẫu ngoại kiểm thì việc đảm bảo độ đồng nhất là yêu cầu bắt buộc được quy định rõ trong ISO 13528:2015.13 Nếu lô mẫu không đảm bảo tính đồng nhất sẽ không được chấp nhận cho mục đích làm mẫu kiểm tra chất lượng xét nghiệm. Số lượng mẫu để kiểm tra độ đồng nhất ở mỗi loài trong nghiên cứu của chúng tôi là 10 lọ dựa trên hướng dẫn của ISO 13528:2015. ${ }^{13}$ Kết quả kiểm tra độ đồng nhất về định danh và kháng sinh đồ các chủng vi khuẩn sau đông khô trong nghiên cứu của chúng tôi hoàn toàn giống với kết quả kiểm tra đặc tính chủng vi khuẩn trước đông khô cho thấy độ đồng nhất của sản phẩm đông khô đạt $100 \%$. Phù hợp với tiêu chuẩn về độ đồng nhất thể hiện trong ISO 13528:2015. ${ }^{13}$

Chúng tôi thực hiện kiểm tra độ ổn định cho mẫu vi khuẩn đông khô trong vòng 6 tháng. Kết quả kiểm tra độ ổn định về định danh và kháng sinh đồ hoàn toàn giống với kết quả kiểm tra độ đồng nhất và kết quả kiểm tra đặc tính chủng vi khuẩn trước đông khô cho thấy độ ổn định của các mẫu đông khô trong nghiên cứu của chúng tôi đạt $100 \%$ phù hợp với tiêu chuẩn về độ ổn định theo ISO 13528:2015. ${ }^{13}$ Từ đó có thể rút ra kết luận rằng thời gian ổn định của mẫu vi khuẩn đông khô trong nghiên cứu của chúng tôi tối thiểu là 6 tháng. Kết quả nghiên cứu của 
chúng tôi tương đồng với kết quả nghiên cứu của tác giả S. Kandil và M. El Soda (2015) và của tác giả N.Đ. Tú và cộng sự (2015). ${ }^{11,14}$ Một số nghiên cứu trên thế giới còn cho thấy thời gian ổn định của mẫu vi khuẩn đông khô kéo dài hơn như nghiên cứu của Yukie Miyamoto và cộng sự (2000) là 10 năm, của Sakane và cộng sự (1997) là 20 năm. ${ }^{10,15}$ Từ cơ sở đó, chúng tôi sẽ tiếp tục theo dõi thời gian ổn định tối đa đối với những chủng trong nghiên cứu này ở thời gian tới.

\section{KÉT LUẬN}

Hoàn thiện quy trình đông khô cho 3 chủng vi khuẩn S. aureus ATCC 29213, E. coli ATCC 25922, P. aeruginosa ATCC 27853 trên thiết bị Virtis Advantage Pro SP Scientific với dung dịch bảo vệ là Skim milk $20 \%$.

Áp dụng quy trình và sản xuất thành công các mẫu vi khuẩn đông khô trên 3 chủng vi khuẩn S. aureus ATCC 29213, E. coli ATCC 25922, P. aeruginosa ATCC 27853 đảm bảo các yêu cầu chất lượng về tính chất vật lý, độ ẩm tồn dư, độ thuần nhất, độ sống, độ đồng nhất, độ ổn định theo tiêu chuẩn ISO 13528:2015, TCVN 9298:2014 và TCN 34:99.

\section{LỜ' CẢM O'N}

Đề tài nghiên cứa của chúng tôi đã nhận được sự hỗ trợ kinh phí của đề án 316/QĐ-TTg về "Tăng cường năng lực hệ thống quản lý chất lượng xét nghiệm y học giai đoạn 2016-2025" của Thủ tướng Chính phủ. Nhóm nghiên cứu cam kết không có xung đột lợi ích với bất kỳ tổ chức, cá nhân nào từ kết quả nghiên cứu.

\section{TÀI LIẸU THAM KHẢO}

1. Quyết định 316/QĐ-TTg ngày 27 tháng 2 năm 2016 của Thủ tướng Chính phủ về phê duyệt đề án tăng cường năng lực hệ thống quản lý chất lượng xét nghiệm y học giai đoạn 2016-2025.
2. Hướng dẫn thực hành kỹ thuật xét nghiệm vi sinh lâm sàng ban hành theo quyết định số 1539/QĐ-BYT ngày 20/4/2017 của Bộ Y tế.

3. Đặng Thị Ngọc Dung, Tạ Thành Văn. Kiểm Soát Chất Lượng Xét Nghiệm - Nội Kiểm và Thống Kê Nội Kiểm Trong Kiểm Soát Chất Lượng Xét Nghiệm y Học. Nhà xuất bản Khoa học và Kỹ thuật; 2018.

4.LeeJJ.ATCCPreservationMethods:Freezing and Freeze-Drying. J Protozool. 1992;39(5):651651. doi:10.1111/j.1550-7408.1992.tb04871.x

5. Tiêu chuẩn quốc gia TCVN 9298-2014 Về vi sinh vật - bảo quản dài hạn vi sinh vật dùng trong nông nghiệp - phương pháp đông khô. Bộ KH\&CN. 2014.

6. Nguyễn Thị Kê, Nguyễn Thị Thế Yến, Huỳnh Ánh Hồng. Nghiên cứu sản xuất Vacxin mẫu chuẩn quốc gia Bạch hầu - Uốn ván - Ho Gà. Viện Vacxin và các chế phẩm sinh học IVAC. 1999.

7. Quyết định số 03/1999/QQD-BNN/TCCB ngày 06/01/1999 về việc ban hành tiêu chuẩn nghành về bảo quản ngắn hạn nguồn gien vi sinh vật nông nghiệp (348-99) và bảo quản dài hạn nguồn gien vi sinh vật nông nghiệp bằng phương pháp đông khô (349-99).

8. Mehaffey MA, Cook EC, Griffin CW. Preparationand stability offreeze-driedNeisseria gonorrhoeae cultures used for external quality control. J Clin Microbiol. 1984;20(6):1126-1129. doi:10.1128/JCM.20.6.1126-1129.1984

9. Griffin W, Cook C, Mehaffey A. Predicting the Stability of Freeze-Dried Fusobacterium mwtiferum Proficiency Testing Samples by Accelerated Storage Tests'. Cryobiology. 1981;18(4):420-425.

10. Miyamoto-Shinohara Y, Imaizumi T, Sukenobe J, Murakami Y, Kawamura S, Komatsu Y. Survival Rate of Microbes after Freeze-Drying and LongTerm Storage. Cryobiology. 2000;41(3):251-255. 
doi:10.1006/cryo.2000.2282

11. Kandil S, El Soda M. Influence of Freezing and Freeze Drying on Intracellular Enzymatic Activity and Autolytic Properties of Some Lactic Acid Bacterial Strains. Adv Microbiol. 2015;05(06):371-382. doi:10.4236/ aim.2015.56039

12. Morgan CA, Herman N, White PA, Vesey G. Preservation of micro-organisms by drying; A review. J Microbiol Methods. 2006;66(2):183193. doi:10.1016/j.mimet.2006.02.017

13. ISO 13528. Statistical methods for use in proficiency testing by interlaboratory comparison. 2015.

14. Nguyễn Đồng Tú, Ngô Tuấn Cường, Lê Thanh Hương. Hoàn thiện quy trình sản xuất và đánh giá độ ổn định của bộ mẫu hỗn hợp vi khuẩn đông khô. Tạp Chí Học Dự Phòng. 2015;XXV:172-173.

15. Sakane, T. Viabilities of dried cultures of various bacteria after preservation for over 20 years and their prediction by the accelerated storage test. Microbiol Cult Coll. $1997 ; 13: 1-7$.

\section{Summary}

\section{PRODUCTION OF LYOPHILYZED BACTERIAL SAMPLE USED IN MICROBIOLOGY QUALITY CONTROL}

The objective of this study is to design a procedure for producing and distributing lyophilized microbiology quality control specimens to laboratories in Viet Nam for improving laboratory quality. The study used Virtis Advantage Pro SP Scientific instrument to lyophilize Staphylococcus aureus ATCC 29213, Escherichia coli ATCC 25922 and Pseudomonas aeruginosa ATCC 27853 with Skimmilk $20 \%$ is cryoprotectant material. The final products are assessed for physical property, survival rate, residual moisture content, purity, homogeneity and stability for 6 months. All of final products meet the criteria for physical properties, the survival densities are $>103 \mathrm{CFU} / \mathrm{mL}$, residual moisture content is $<4 \%$, purity and homogeneity are $100 \%$ and products are stable for at least 6 months. In conclusion, the lyophilization procedure is acceptable for producing lyophilized microbiology quality control specimens from three bacterial strains as above.

Keywords: Lyophylization, homogeneity, stability, survival, microbiology quality control 